\title{
La necesidad de una interpretación pro discriminado de la acción judicial contra la discriminación
}

\author{
Fernando Muñoz León*
}

\begin{abstract}
RESUMEN
Este artículo sostiene que la acción judicial contra la discriminación establecida en la Ley $N^{\circ} 20.609$ debe ser objeto de lo que se denominará como una interpretación pro discriminado. Ella consiste en una comprensión de dicha acción que dé relevancia a la noción de categorías protegidas, que flexibilice la carga probatoria que debe soportar inicialmente el demandante, que haga posible la atribución de responsabilidades en materia de prueba y justificación al demandado, y que conduzca a la adopción de medidas de reparación del acto discriminatorio efectivas y preventivas.
\end{abstract}

Derecho antidiscriminación - igualdad constitucional - interpretación legal

\section{The need for a pro discriminatee interpretation of the judicial remedy against discrimination}

\begin{abstract}
This article argues that the remedy against discrimination of Statute $N^{\circ} 20.609$ must be the object of what will be labeled as a pro discriminatee interpretation. This consists in an understanding of this remedy that gives relevance to the notion of protected categories, that makes possible the alleviation of the evidentiary burden of the plaintiff, that makes possible the allocation of duties of proof and persuasion to the defendant, and that makes possible the adoption of effective and preventive measures for the reparation of distinct acts of discrimination.
\end{abstract}

Antidiscrimination law - constitutional equality - legal interpretation

* Licenciado en Ciencias Jurídicas, Pontificia Universidad Católica de Chile. Doctor en Ciencias Jurídicas, Universidad de Yale, Estados Unidos. Profesor de Derecho, Universidad Austral de Chile. Correo electrónico: fernando.munoz@uach.cl

Este artículo forma parte del Proyecto de Investigación Fondecyt Regular No 1180895 , "Discriminación y Trabajo".

Artículo recibido el 1 de abril de 2017 y aceptado para su publicación en este número el 23 de julio de 2018 


\section{INTRODUCCIÓN}

$\mathrm{N}$ umerosos países cuentan ya con un derecho antidiscriminación constituido plenamente como una rama relativamente específica del saber jurídico y de la práctica jurisprudencial que, con el fin de contribuir con el cumplimiento del objetivo constitucional de proteger a toda la ciudadanía por igual en el ejercicio de sus derechos, desarrolla conceptos y doctrinas jurídicas orientadas a proteger a los integrantes de colectivos sociales que han recibido históricamente un trato social desaventajado (Khaitan, 2014) ${ }^{1}$. Pero ya transcurridos seis años desde la entrada en vigencia de la Ley No 20.609, de Medidas contra la Discriminación, la pregunta respecto de si la jurisprudencia nacional emanada de la acción judicial contra la discriminación ha contribuido al surgimiento en nuestro país de un sólido derecho antidiscriminación mediante la elaboración jurisprudencial de un poderoso y sofisticado arsenal de doctrinas jurídicas que contribuyan a la erradicación de este fenómeno sigue teniendo una respuesta más bien negativa, como lo sugieren investigaciones que han revisado críticamente la jurisprudencia recaída sobre la acción judicial contra la discriminación (Casas y Lagos, 2014; Muñoz, 2015).

Resulta de gran importancia observar que la jurisprudencia referida, al momento de conceptualizar qué es lo que hace que un determinado acto sea discriminatorio, tiende a recurrir a la tradicional definición de la discriminación arbitraria elaborada por las cortes en el marco de la acción constitucional de protección, que entiende la garantía del artículo $19 \mathrm{~N}^{\circ} 2$ de la Constitución no como una exigencia de forma alguna de igualdad material sino meramente como una prohibición de conductas irracionalmente arbitrarias. Esta forma de definir el concepto de igualdad se limita, en lo substantivo, a censurar actos extremadamente arbitrarios y, en cuanto a lo metodológico, tiende a aislar el escrutinio judicial de la razonabilidad del actuar del demandado de toda discusión del contexto social, tanto simbólico como material, que rodea a la conducta en cuestión, contexto que a menudo constituye un elemento imprescindible para lograr caracterizar un determinado acto como discriminatorio según la significación específica de este término de marginación social prejuiciosa de un determinado tipo de personas en razón de atributos como su identidad racial o sexual. El concepto de discriminación arbitraria, en ese sentido, puede ser legítimamente calificado de formalista según la comprensión de este término que lo define en referencia a su intensa clausura cognitiva frente a los elementos situacionales que rodean al análisis jurídico.

No es de extrañar, en consecuencia, y pese a numerosas expectativas en contrario, que la acción judicial contra la discriminación haya producido escasos resultados. Es posible mencionar que entre diciembre de 2012 y abril de 2017 han existido tan solo 89 sentencias definitivas de primera instancia recaídas sobre demandas tramitadas de acuerdo con la Ley $\mathrm{N}^{\circ} 20.609$, de estas tan solo 26 han fallado a favor del demandante.

${ }^{1}$ Al referirme al derecho de la antidiscriminación estoy dejando de lado las medidas de política pública orientadas a lograr una mayor inclusión de los individuos pertenecientes a colectivos discriminados como cuotas, subsidios, u otras políticas de acción afirmativa. 
Tampoco es sorpresivo constatar que la aplicación judicial de la Ley de Medidas contra la Discriminación ha estado lejos de satisfacer las expectativas sociales creadas en torno a este cuerpo legislativo. Una de las organizaciones sociales que participaron activamente en la tramitación de este cuerpo legislativo ha afirmado en su XII Informe Anual de Derechos de la Diversidad Sexual (Movimiento de Inclusión y Liberación Homosexual $2013,157)$ que "el mecanismo judicial de la Ley No 20.609 no está siendo utilizado por gran parte de las personas que sufren discriminación y, cuando se usa, pocas veces deriva en justicia”. El XIV Informe de la misma organización (Movimiento de Inclusión y Liberación Homosexual 2015, 214-17), de hecho, no duda en titular su acápite acerca de esta temática de la siguiente manera: "Ley Zamudio en Crisis". Esta crisis, por cierto, no afecta solamente a quienes sufren discriminación; también constituye un grave problema de legitimidad social del legislador, cuya intervención en esta materia fue requerida por la opinión pública al momento de la muerte del joven Daniel Zamudio.

Sin duda, la Ley $\mathrm{N}^{\circ} 20.609$, como han observado varios académicos ${ }^{2}$, adolece de numerosos problemas de técnica legislativa. Sin embargo, si bien ella ofrece un precario punto de partida para el surgimiento del derecho antidiscriminación nacional, ello no debe ser obstáculo para que la academia y los tribunales contribuyan mediante la elaboración de un repertorio jurídico doctrinal que desarrolle maneras de dar protección efectiva a los derechos de las personas discriminadas. Como han aseverado Casas y Lagos (2014, 136-37), "algunos de los problemas que presenta la Ley No 20.609 pueden corregirse sin necesidad de reformas legislativas, sino que efectuando una interpretación pro persona y de buena fe de la normativa”. Siguiendo su observación, en lo que queda de esta sección sostendré que interpretar la normativa que establece la acción judicial contra la discriminación en un sentido que sea coherente con los principios fundamentales del ordenamiento constitucional supone interpretarla siguiendo lo que aquí denominaré como principio pro discriminado. Posteriormente, en las secciones I, II y III ofreceré argumentos concernientes a lo que una interpretación pro discriminado de dicha acción judicial implica en materia de conceptualización, prueba, justificación y reparación de la discriminación.

El principio pro discriminado como mandato bermenéutico finalista, sistemático y eficaz

La vulnerabilidad y el desempoderamiento que acompañan al fenómeno discriminatorio se asemeja a otras posiciones de relativa debilidad bien conocidas por el derecho, así como la situación del individuo enfrentado al poder punitivo estatal o la situación del trabajador enfrentado al poder de mando de su empleador. Esta analogía nos sugiere que la misma racionalidad que recomienda la adopción en el derecho penal del principio pro reo y en el derecho laboral del principio pro operario recomienda la adopción de un similar principio pro discriminado como criterio rector del derecho antidiscriminación. La

${ }^{2}$ Diversos autores han observado críticamente esta cuestionable calidad técnica; véanse CoDDOU y Vial (2013), Coddou et al. (2013), Díaz (2013), Díaz de Valdés (2013) y Vial (2013). 
característica estructural de todos estos principios jurídicos es que proponen enfrentar una desigualdad social con lo que podríamos denominar como una inversión jurídica de las posiciones mediante la creación de excepciones a la racionalidad jurídica normal que favorecen a la parte considerada como socialmente más débil.

Lo interesante de principios como pro reo y pro operario es que, al igual que ocurre con la invocación retórica de nociones como las de dignidad o estado de derecho, su vigencia y su carácter vinculante en el discurso constitucional contemporáneo no parece ser puramente positiva, en cuanto no se funda meramente en la vigencia de cláusula constitucional alguna. La vigencia y obligatoriedad de este tipo de principios reposa en que son percibidos tanto por juristas como por ciudadanos como exigencias de justicia material basadas en el trato igualmente digno que un Estado constitucional le debe a sus ciudadanos. La historia misma de los principios pro reo y pro operario lo confirma, pues los debemos a los grandes momentos fundacionales del Estado constitucional moderno; el principio pro reo, a la ilustración jurídica y las revoluciones burguesas; el principio pro operario, al giro social de la tradición constitucional al calor de las demandas obreras. El profundo cambio social y cultural que han experimentado las sociedades occidentales en las últimas décadas, unido a la creciente conciencia contemporánea acerca de la dignidad de todas las personas sin exclusión alguna, constituyen el contexto histórico que nos permite extender analógicamente esta misma racionalidad hacia la proclamación, como exigencia de justicia material, de un principio pro discriminado como eje del derecho antidiscriminación en la lucha contra el persistente fenómeno social de la discriminación.

En el marco del derecho antidiscriminación, el principio pro discriminado nos invita a darle a las normas contra la discriminación una interpretación finalista, sistemática y eficaz. Una interpretación finalista de las normas respecto de discriminación enfatiza que el objetivo que persiguen las normas contra la discriminación es, precisamente, combatir la discriminación o, dicho en términos más concretos, poner fin a conductas discriminatorias, reparar los daños producidos por ellas, y evitar su reiteración en lo sucesivo, compensando así el relativo desempoderamiento de los individuos pertenecientes a grupos históricamente desaventajados. El principio pro discriminado es la formulación de dicho fin como guía hermenéutica.

La adopción de un principio pro discriminado es consciente de la importancia de una interpretación e integración sistemática del conjunto de normas contra la discriminación vigentes en nuestro sistema jurídico. Esta interpretación, hasta el momento, ha tendido a ser postergada por la jurisprudencia, que salvo excepciones muy contadas no ha llegado a preguntarse cómo se articulan normas contra la discriminación contenidas en fuentes tan diversas como la Constitución Política de la República, diversos tratados internacionales, códigos como el del Trabajo y el Código Penal, leyes como la Ley sobre Protección de los Derechos de los Consumidores, y la heterogénea legislación de específicos colectivos discriminados, además de la Ley de Medidas contra la Discriminación. Está todavía pendiente la construcción de un conjunto de estrategias de conceptualización, análisis y razonamiento jurídico que permita la integración de todas estas fuentes normativas en una corriente jurisprudencial antidiscriminación vigorosa y efectiva en el cumplimiento del telos de la antidiscriminación. 
Finalmente, el principio pro discriminado enfatiza la necesidad de una interpretación eficaz de la acción judicial contra la discriminación. El Pacto Internacional de Derechos Civiles y Políticos proclama la efectividad en la tutela judicial contra la discriminación como un objetivo fundamental en su artículo 26, señalando que en los Estados parte "la ley prohibirá toda discriminación y garantizará a todas las personas protección igual y efectiva contra cualquier discriminación por motivos de raza, color, sexo, idioma, religión, opiniones políticas o de cualquier índole, origen nacional o social, posición económica, nacimiento o cualquier otra condición social”. La efectividad en materia de discriminación presenta particulares desafíos, debido precisamente a la posibilidad de que la acción conjunta de estereotipos y de prácticas de trato desigual pueda obstaculizar el propio esfuerzo contra la discriminación, haciéndole sucumbir al fenómeno que está intentando contrarrestar. La adopción de un principio pro discriminado en la interpretación, integración y aplicación de las normas contra la discriminación debiera compensar dicho riesgo, incorporando una sensibilidad al contexto similar a la que caracteriza al principio iuslaboral de primacía de la realidad.

\section{HACIA UNA RECONCEPTUALIZACIÓN DE LA DISCRIMINACIÓN ARBITRARIA:}

\section{LA CONVENIENCIA DE DISTINGUIR ENTRE ARBITRARIEDAD}

\section{Y DISCRIMINACIÓN}

Como ha sido ya señalado, la interpretación judicial de la acción contra la discriminación se ha visto perjudicada por una recepción poco crítica de la comprensión tradicional del mandato constitucional de igualdad y no discriminación elaborada por los tribunales superiores conociendo del recurso de protección. Ello ha permitido que la jurisprudencia en la acción de no discriminación mantenga los déficits que caracterizaban a la jurisprudencia respecto del recurso de protección en materia de igualdad y no discriminación.

Es factible señalar que el proceso que condujo a la presentación del proyecto de ley que se transformó en la Ley N 20.609 estaba motivado precisamente por la inutilidad del recurso de protección como instrumento para el combate a la discriminación (Movimiento de Inclusión y Liberación Homosexual 2002, 16). Recordemos el estado de la cuestión a comienzos del 2000. En aquel entonces, diversos observadores habían llegado a la conclusión de que la jurisprudencia de protección en materia de igualdad, para ponerlo en términos del análisis que hiciera Atria (1997), carecía de criterios que permitan interpretar y aplicar de manera sistemática los contenidos del artículo 19 $\mathrm{N}^{\circ} 2$ de la Constitución Política de la República, es decir, el mandato de tratamiento igualitario y la prohibición de discriminaciones arbitrarias. Según Atria, todo lo que uno podía obtener de dicha jurisprudencia eran vaguedades tales como que es necesario tratar "igual a los iguales y diferente a los diferentes" o que una conducta arbitraria es aquella que no está "gobernada por la razón”. Pero el razonamiento empírico y normativo que permitiría saltar de esas generalidades a decisiones específicas en casos concretos, observó Atria, brillaba por su ausencia. De ello resultaba, como observaran por su parte 
Figueroa y Gómez $(2000,19)$, que en este tipo de casos “las cortes prácticamente nunca discurren acerca de la discriminación; no suelen pronunciarse si existe o no, o en qué consiste, o cuáles serían criterios de discriminación prohibidos o permitidos”3.

Esta última observación es crucial, porque evidencia cuál es la consecuencia de carecer de un instrumental de conceptos jurídicos inadecuado para lidiar con el fenómeno de la discriminación. Si los tribunales no analizan cuidadosamente mediante sus sentencias la manera en que los casos que se les presentan se vinculan con las problemáticas sociales más amplias de la discriminación, la capacidad de acumular jurisprudencialmente aprendizajes acerca de cómo combatir la discriminación se vuelve nula. Aquí se evidencia la importancia que detentan los conceptos en la producción de conocimiento jurídico de la realidad social, pues ellos funcionan como "entradas" de un diccionario o una enciclopedia: si no existe el concepto apropiado, la "entrada" no podrá ser rellenada. En este caso, si no se cuenta con una conceptualización de la discriminación que evidencie las interconexiones estructurales que cada evento discriminatorio tiene con las complejas estructuras sociales que perpetúan la discriminación, resultará difícil que los tribunales desarrollen un saber teórico-práctico referente a las maneras más efectivas en que pueden no solamente poner fin a conductas discriminatorias concretas y reparar adecuadamente a sus víctimas, sino también irrumpir las prácticas sociales discriminatorias en las que se insertan aquellos actos individuales y modificar los discursos y las mentalidades discriminatorias que dan sustento ideológico a aquellas prácticas discriminatorias.

El formalismo que caracteriza a la comprensión tradicional de la discriminación arbitraria hace aconsejable que no nos quedemos únicamente con esa forma de entender el concepto en cuestión al momento de darle operatividad a la definición de discriminación arbitraria propuesta por el legislador en el artículo $2^{\circ}$ de la Ley $\mathrm{N}^{\circ}$ 20.609. Resulta necesario construir un espacio conceptual para que dicha definición pueda ser entendida por el intérprete de una manera que sea útil al propósito de combatir el flagelo social de la discriminación. Quisiera sugerir que, con el fin de preservar los méritos que la concepción tradicional pueda tener en la rápida identificación de afectaciones arbitrarias a derechos fundamentales compensando sus carencias en la identificación de situaciones más complejas de discriminación, es conveniente diferenciar dos conjuntos de hipótesis de vulneración del derecho al trato igualitario y de infracción a la correlativa prohibición de la discriminación arbitraria establecidos en el conjunto normativo compuesto por el

${ }^{3}$ Ello, desde luego, tiene mucho que ver con las particularidades y limitaciones intrínsecas del recurso de protección, el que Couso (2005), reflexionando en términos más generales, ha caracterizado como la promesa de una "revolución de derechos" que no ha llegado a ser realizada. La razón de esto ha sido explicada con claridad por Bordalí (2006): al haber sido ideado durante la dictadura como un procedimiento orientado a proteger la propiedad contra posibles requisiciones similares a las que llevó a cabo el gobierno de Salvador Allende, el diseño del procedimiento de protección no se hizo cargo de las exigencias propias de un procedimiento ni de declaración ni de protección de derechos fundamentales, lo que se ha expresado particularmente en la práctica inexistencia de una fase contradictoria propiamente tal en dicho procedimiento, reemplazada a medias mediante la exigencia de un "informe" del recurrido, y la completa inexistencia de una fase probatoria, la que a menudo es imprescindible en este tipo de procesos. 
artículo $19 \mathrm{~N}^{\circ} 2$ de la Constitución y el artículo 2 de la Ley $\mathrm{N}^{\circ} 20.609$. Denominaré a estos conjuntos de hipótesis, respectivamente, como hipótesis de arbitrariedad e hipótesis de discriminación o, más sucintamente, como arbitrariedad y discriminación.

Con el fin de ilustrar estas categorías comenzaré describiendo cuatro situaciones ${ }^{4}$. En el primer ejemplo, una institución pública que entrega becas de estudio margina de un concurso a un postulante que había criticado a la institución en un periódico de circulación nacional. En el segundo caso, una federación de rodeo le impone a uno de sus integrantes, que había criticado en público a su directiva, la sanción de expulsión en un procedimiento irregular. En el tercer ejemplo, una agrupación de bomberos rechaza la postulación de una mujer debido a que la mayoría de sus integrantes considera que la presencia de una mujer entorpecería las labores que deben realizar. En el cuarto ejemplo, el administrador de un motel para parejas se niega a arrendar una habitación a una pareja de lesbianas porque su presencia podría molestar a otros clientes. Si bien en los cuatro ejemplos un determinado individuo ha recibido un trato perjudicial basado en consideraciones ilegítimas, la forma diversa en que las consideraciones que motivan dicho trato interactúan con el entorno social aconseja darles un tratamiento conceptual y práctico diferenciado.

\section{La arbitrariedad como lesión injustificada de intereses individuales valiosos}

Si en el primer caso estamos frente a una afectación de la libertad de expresión por parte de una autoridad sometida al principio de legalidad, en el segundo caso nos encontramos con una vulneración de la garantía del debido proceso que ha perturbado el ejercicio de las libertades de asociación y de expresión. Desde la creación del recurso de protección ha sido frecuente que este tipo de casos sea confrontado por los tribunales recurriendo al artículo $19 \mathrm{~N}^{\circ}$ 2, lo que explica que casos de este tipo hayan sido litigados también mediante la acción judicial contra la discriminación. Sin embargo, la discusión jurisprudencial de este tipo de casos ha tendido a ignorar la analíticamente compleja pregunta de qué justifica que este tipo de casos sean catalogados como problemas de discriminación arbitraria.

Diferenciar entre hipótesis de arbitrariedad e hipótesis de discriminación contribuye significativamente a facilitar la justificación de dicha clasificación. Si pensamos en la arbitrariedad como una infracción autónoma a la prohibición de la discriminación arbitraria veremos que existen ciertos sujetos que a la luz de los principios del Estado constitucional de derecho debieran estar siempre prohibidos de actuar arbitrariamente en el sentido de actuar caprichosamente o sin justificación (lo que no siempre es lo mismo), mientras que hay otros sujetos que están exentos de tal estándar. Así, una

${ }^{4}$ Estos ejemplos corresponden a casos efectivamente litigados mediante la acción judicial contra la discriminación, los que aquí presento en la versión de sus respectivos demandantes -es decir, sin atender a la versión de los demandados ni a aquella que el tribunal abrazó como verdad judicial- a fin de servir propósitos explicativos. 
primera hipótesis de arbitrariedad está compuesta de aquellos casos en donde los órganos del Estado afectan gravemente intereses legítimos de particulares careciendo de una justificación legítima y suficiente. Para estos órganos, sujetos al principio de juridicidad, la prohibición constitucional de la discriminación arbitraria se traduce, en términos positivos, en una exigencia de conducta racionalmente fundada. En cambio, en el caso de los particulares, cuya autonomía personal les impone en su conducta privada menores exigencias de racionalidad y mayores márgenes de razonabilidad que los que el principio de legalidad le impone al Estado, para que una conducta que afecte gravemente intereses legítimos de terceros pueda ser calificada de arbitraria se ha de exigir una irracionalidad particularmente manifiesta o intensa. Una segunda hipótesis de arbitrariedad, entonces, está integrada por conductas manifiesta o intensamente irracionales de particulares que lesionan gravemente intereses legítimos de terceros.

En ambas hipótesis estamos frente a conductas que afectan intereses individuales valiosos careciendo de una justificación idónea. Ellos nos permiten definir la arbitrariedad, en términos generales, como una lesión injustificada de intereses individuales valiosos. Este tipo de casos se adecua a la clásica definición de discriminación arbitraria de la Corte Suprema: un "actuar irracional o caprichoso, esto es, con voluntad no gobernada por la razón” (Repertorio de Legislación y Jurisprudencia chilenas 1996, 133), y que ha constituido un modelo normativo inadecuado para el combate contra el fenómeno social de la discriminación. En este tipo de casos, es posible que la jurisprudencia se enfrente a una variedad heterogénea e ininteligible de casos que no tengan mucho en común entre sí y respecto de los que no se puedan establecer líneas jurisprudenciales ni desarrollar conceptos y doctrinas de mediano alcance. Sin perjuicio de ello, este concepto sí parece ser un marco conceptual adecuado para el tratamiento de conductas que no respondan a problemáticas sociales generalizadas, sino a conductas aisladas de individuos que puedan ser efectivamente calificadas como caprichosas, irracionales, y arbitrarias. De ahí que en este tipo de casos haya simplemente un problema de justicia conmutativa, circunscrito a las partes efectivamente involucradas en el proceso.

Un proceso jurisdiccional empleado para remediar la arbitrariedad no exige, entonces, una alteración de las lógicas procesales ordinarias, que ven el proceso judicial como "un enfrentamiento entre dos sujetos privados -las partes procesales- que se encuentran en total igualdad entre ellos", y en donde "no importa la situación material en que se encuentran las personas tras el ropaje de parte procesal” (Bordalí, 2013, 217). En esta contienda entre actor y defensor se realizan dos discusiones: una fáctica o probatoria, que gira en torno a la veracidad de los medios probatorios proporcionados por el actor, y una normativa o justificatoria, donde se discute la justificabilidad del trato dado al demandante por el demandado. En ambos casos, recae exclusivamente sobre el demandante la responsabilidad de convencer al juez, tanto por la efectividad de su relato de los hechos como de su pretensión normativa de que la conducta del demandado carece de justificación. Por ello, el demandado habrá de prevalecer en el litigio, incluso si permanece en la inacción, cuando el demandante no presente pruebas que por sí solas le 
den veracidad a su relato de los hechos; o cuando el demandante no ofrezca argumentos normativos que logren persuadir al juez de que el defensor no debió haber realizado la acción sometida a escrutinio o debió haber subsanado la omisión denunciada. Si el actor ofrece pruebas y argumentos persuasivos, el juez calificará la conducta como arbitraria; si el actor fracasa en dicha tarea, el juez calificará la conducta como justificada. La reparación, a su vez, buscará simplemente restituir al demandado a su posición original, sin que sea necesario, particularmente, adoptar medidas orientadas a la transformación de mentalidades colectivas ni prácticas sociales.

\section{La discriminación como conducta discriminatoriamente perjudicial}

En el tercer y cuarto caso tenemos conductas que un examen que no tome en consideración su significado a la luz del contexto social estructural podría considerar como legítimas dentro de los márgenes ofrecidos por la autonomía personal y su proyección en materia de libre asociación, en el primer caso, y de libre actividad económica, en el segundo. A la luz de dicho contexto, sin embargo, se vuelve evidente la contradicción de estas conductas con una concepción substantiva de la igualdad constitucional que entienda al fenómeno discriminatorio como una vulneración estructural a la garantía de no discriminación.

Los casos de discriminación, como es evidente, están causalmente vinculados con las complejidades e injusticias de la estructura social. Estos problemas sociales, desde luego, no pueden ser resueltos satisfactoriamente y a cabalidad mediante la rectificación de la concreta conducta discriminatoria sometida al conocimiento de los tribunales. Así y todo, cada caso que es judicializado ofrece, al menos, la oportunidad, además de reparar el caso concreto, de visibilizar estos problemas sociales, abordarlos institucionalmente, acumular aprendizajes de cómo morigerarlos, y transmitir a la sociedad la señal de que se trata de conductas que contrarían valores y compromisos fundamentales del Estado constitucional.

Distinguir entre arbitrariedad y discriminación como hipótesis de infracción a la prohibición de la discriminación arbitraria nos permite destacar conceptualmente aspectos de la discriminación que hasta el momento se han mantenido en la periferia del razonamiento jurisprudencial y que, sin embargo, son precisamente centrales en la conceptualización del fenómeno de la discriminación. Me refiero, en particular, a las consideraciones adscriptivas que estructuran la discriminación en torno a atributos como la identidad racial o sexual. Darle relevancia a esta dimensión de la discriminación nos permite dar cuenta del efecto logrado por la Ley $\mathrm{N}^{\circ} 20.609$, que incluyó como elemento protagónico de la definición legal de la igualdad constitucional el reconocimiento de que existen colectivos de personas discriminadas en razón de diversos atributos adscriptivos que requieren de una protección jurídica reforzada.

En función de ello, parece adecuado definir la discriminación en cuanto infracción autónoma a la prohibición de la discriminación arbitraria como aquella conducta que perjudica injustificadamente los intereses legítimos de terceros en razón de criterios 
discriminatorios. A continuación daré cuenta de los términos de esta definición, concentrándome en las nociones de conducta, perjuicio injustificado, y criterios discriminatorios.

Por conducta debemos entender de manera amplia toda "distinción, exclusión o restricción”; ello incluye, naturalmente, no solamente actos positivos sino también omisiones, posibilidad esta última que adquiere una gran importancia en asuntos como la determinación de patrones discriminatorios de selección de personal en instituciones públicas y empresas privadas. La existencia de una determinada conducta comisiva u omisiva es un asunto fáctico sujeto a prueba, la que debe ser rendida de acuerdo con los criterios que se enunciarán más adelante; si dicha conducta es constitutiva o no de discriminación es, en cambio, un asunto de calificación jurídica que requiere formular un juicio normativo respecto de la justificación que ofrezca el acusado.

Este juicio supone determinar si la conducta ha producido un perjuicio injustificado a los intereses de determinados terceros. Esta definición protege contra posibles perjuicios una esfera más amplia de intereses de terceros, los que pueden ya no resultar intrínsecamente tan valiosos para sus titulares pero que al interactuar con la ilicitud de la conducta discriminatoria pasan a verse protegidos. Quizás no sea muy grave desde el punto de vista constitucional el verse excluido de una asociación privada; pero sí lo es cuando esta exclusión está motivada por la raza u orientación sexual del excluido. En el caso de los particulares, adicionalmente, la hipótesis de discriminación así definida les impone un estándar de racionalidad más exigente que el que les plantea la hipótesis de arbitrariedad. Por todo ello, la hipótesis de discriminación sanciona conductas que no habrían sido sancionables bajo la hipótesis de arbitrariedad. Diferenciar entre arbitrariedad y discriminación también nos ayuda a comprender la intensidad prohibitiva de esta segunda hipótesis y la reducción que produce del margen de razonabilidad en la conducta de los particulares. Si entendemos que la prohibición constitucional de la discriminación arbitraria es una prohibición del más alto rango normativo dirigido contra toda conducta motivada por criterios discriminatorios, entonces no resulta difícil traducir esta prohibición en un mandato positivo dirigido a todos los particulares de abstenerse de realizar conductas discriminatorias.

Que la producción del perjuicio o la desventaja motivada por criterios aparentemente discriminatorios sea injustificada significa que, de la evidencia fáctica y de los argumentos explicativos de la situación ofrecidos por las partes, el juez puede razonablemente concluir que la justificación legítima invocada por el demandado es insuficiente. Las alegaciones del demandado deberán ser sometidas a un análisis riguroso y exigente de su coherencia y razonabilidad. Puede ocurrir que el demandado considere que su conducta es legítima o "razonable" debido a que se justificaría en el "ejercicio legítimo" de otro derecho fundamental o "en otra causa constitucionalmente legítima”. En este caso, si bien el demandado ha sido capaz de ofrecer una fundamentación legítima, ella habrá también de ser evaluada por el tribunal mediante un escrutinio estricto, el que tendrá por objetivo evaluar la intensidad fáctica y jurídica del daño causado y determinar si ha de prevalecer, en relación con la conducta denunciada, el reproche o su justificación.

La conducta lesiva de intereses de terceros se vuelve discriminatoria si ha sido motivada por los criterios discriminatorios identificados de manera ejemplar por el legislador 
en el artículo $2^{\circ}$ de la Ley $\mathrm{N}^{\circ}$ 20.609; es decir, "motivos tales como la raza o etnia, la nacionalidad, la situación socioeconómica, el idioma, la ideología u opinión política, la religión o creencia, la sindicación o participación en organizaciones gremiales o la falta de ellas, el sexo, la orientación sexual, la identidad de género, el estado civil, la edad, la filiación, la apariencia personal y la enfermedad o discapacidad”. No está de más enfatizar que lo que la norma busca no es excluir la utilización de un criterio o marcador adscriptivo de identidad sino proporcionarle una protección intensificada a la persona y los derechos de los individuos que pertenecen a categorías de personas que han sido históricamente desaventajadas cuando enfrenten conductas que afecten sus intereses estando motivadas por criterios discriminatorios.

\section{LA RECEPCiÓN DE LA CAUSA A PRUEBA Y LA SANA CRÍTICA COMO ESPACIOS PARA LA FLEXIBILIDAD Y EL DINAMISMO EN LA ATRIBUCIÓN DE CARGAS PROCESALES}

La posibilidad de que los jueces faciliten las obligaciones probatorias del demandante y atribuyan responsabilidades probatorias y justificatorias al demandado es fundamental para la existencia de un proceso antidiscriminación efectivo. Las características del fenómeno discriminatorio exigen la posibilidad de contar con este mecanismo como remedio para compensar las desigualdades simbólicas y materiales existentes en la realidad social y que participan de la producción de la discriminación, las que pueden resultar en una efectiva desigualdad procesal entre ambas partes.

Nuestro sistema jurídico carece de una instrucción legislativa que explícitamente señale que, en el marco de la acción contra la discriminación de la Ley $\mathrm{N}^{0} 20.609$, los jueces puedan modificar las lógicas habituales de atribución de la carga de probar hechos y argumentar en favor de la justificación de conductas. Ahora bien, nuestro sistema jurídico no dista de las circunstancias en las que se encontraban los sistemas jurídicos de Estados Unidos norteamericano y de la Unión Europea comunitario-europeo en el momento en que sus tribunales establecieron la posibilidad de alterar las reglas habituales del proceso civil en casos de discriminación. En ambos casos, la flexibilidad en la atribución de cargas procesales ha provenido de interpretaciones de normas contra la discriminación elaboradas por los tribunales que perfectamente podrían ser calificadas como ejemplos de interpretación pro discriminado.

En el caso de Estados Unidos esto ocurrió con la sentencia McDonnell Douglas Corp v. Green (1973), en donde la Corte Suprema de ese país resolvió un caso en que un trabajador afroamericano alegó que su exempleador tenía prácticas laborales que vulneraban las normas contra la discriminación en el empleo contenidas en el Título VII de la Ley de Derechos Civiles de 1964. En su sentencia, la Corte estableció que, en el caso de que un demandante ofreciera pruebas que prima facie sugirieran la existencia de una conducta discriminatoria, la responsabilidad de ofrecer evidencia que establezca que se trató de una conducta legítima y no discriminatoria debe desplazarse al demandado; para decirlo en las palabras de la Corte, burden then must shift. 
En el caso de la Unión Europea, la Corte Europea de Justicia acogió la posibilidad de desplazar cargas procesales en juicios por discriminación en el caso Danfoss (1988), en donde un sindicato demandó a una empresa por prácticas salariales discriminatorias entre hombres y mujeres. En su sentencia, la Corte afirmó que "en una situación en la que se discute un mecanismo de incrementos individuales de salarios, caracterizado por una falta total de transparencia", y en el que las trabajadoras "no pueden establecer diferencias más que entre retribuciones medias", es decir, no pueden demostrar positivamente que existe una determinación o intención de carácter discriminatorio, ellas "estarían privadas de todo medio eficaz de hacer respetar el principio de igualdad de retribución ante el órgano jurisdiccional nacional, si el hecho de aportar esta prueba no tuviera por efecto trasladar al empresario la carga de la prueba de que su política de salarios no es discriminatoria en realidad" ( $\$ 13)$. El destacado añadido busca enfatizar precisamente el tipo de razonamiento que se promueve aquí, es decir, la necesidad de que las normas antidiscriminación sean objeto de una interpretación que opte por su reconstrucción más favorable a los sujetos beneficiarios de la protección, lo que supone optar por una interpretación eficaz de la misma; volviendo a las palabras de la Corte, "la preocupación por la eficacia que inspira a la Directiva [de la Unión Europea sobre igualdad de remuneraciones] debe llevar a interpretarla en el sentido de que incluye la modificación de las normas nacionales relativas a la carga de la prueba en las situaciones especiales en que tales modificaciones sean indispensables para la aplicación efectiva del principio de igualdad” ( $\$ 14)$.

En consecuencia, la pregunta para nuestro sistema jurídico, desde una perspectiva hermenéutica pro discriminado, es si existen en nuestro sistema jurídico espacios de flexibilidad interpretativa que permitan, en el marco de la acción judicial contra la discriminación, facilitar la obligación de probar del demandante y desplazar al demandado la carga de alegar la justificabilidad o legitimidad de su conducta. La respuesta, a mi juicio, es positiva: la determinación de la contienda probatoria y argumentativa mediante el auto de prueba, y la evaluación de las argumentaciones de hecho y de derecho a la luz del estándar de la sana crítica, ofrecen dicha flexibilidad interpretativa. Esto supone reinterpretar, dentro del marco del proceso antidiscriminación, las obligaciones procesales del demandante y del demandado.

\section{La obligación de probar del demandante como obligación de aportar indicios probatorios}

En una hermenéutica pro discriminado de la acción contra la discriminación, la obligación del demandante de probar, que en el proceso civil clásico consiste en una obligación de aportar toda la prueba necesaria para establecer la existencia de un daño o un incumplimiento de obligaciones por parte del demandado, debe ser reinterpretada como una obligación de aportar indicios probatorios, es decir, de ofrecer una relación razonablemente coherente de los hechos acompañada de evidencia probatoria que permita sustentar la plausibilidad de su relato en alguna evidencia externa al propio discurso del demandado. Al juez le debiera bastar con la presentación de la demanda, la que debiera 
indicar de qué medios de prueba se valdrá para determinar si procede la atribución de obligaciones de probar al demandado mediante el auto de prueba.

Si bien esta reinterpretación supone un cambio de las lógicas del procedimiento civil, es importante observar que ella no llega al extremo de dar por probados los hechos mediante la mera presentación de la demanda, ni tampoco de dejar en la indefensión al demandado. Como ha explicado Ugarte $(2009$, 219) respecto de este mecanismo en el proceso laboral, "no es suficiente que se alegue una lesión de derechos fundamentales para que se traslade al [demandado] la carga probatoria, y por ello, en rigor, a pesar de la confusión de algunos, no se altera el axioma de que corresponde probar un hecho al que lo alega", pues el demandante "no está completamente liberado de prueba: debe acreditar la existencia de indicios suficientes de la existencia de la conducta lesiva”.

La posibilidad de atribuir al demandado obligaciones de probar y de justificar mediante el auto de prueba, y su evaluación mediante un escrutinio estricto

En la interpretación pro discriminado que propongo de la acción contra la discriminación, la existencia en la demanda de una narrativa de los hechos que se denuncien como discriminatorios que resulte plausible a la luz de las máximas de la experiencia, acompañada del ofrecimiento de medios probatorios que refuercen dicha plausibilidad, debiera llevar al juez a dictar un auto de prueba en que se atribuya al demandado la responsabilidad de aportar elementos probatorios que derriben la veracidad del relato del demandante, así como de argumentar que dicha conducta no ha sido constitutiva, normativamente hablando, de discriminación.

Esta posibilidad ha sido concebida con cierta claridad por unas pocas sentencias dictadas en materia de acción contra la discriminación. Así, una de ellas señala que, "establecida la existencia de un hecho discriminatorio [...] se produce un traslado de la carga probatoria, correspondiendo [también] al denunciado el acreditar la racionalidad o fundamentación de su actuar" 5 . Otra sentencia señala que "correspondía a la demandada

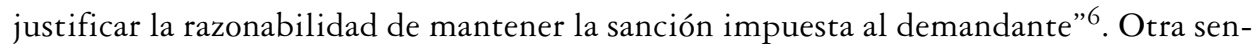
tencia reciente señala, en cuanto al requisito de falta de razonabilidad o justificación, "al haberse dado por establecido la existencia de la distinción de trato realizada por el [demandado], correspondía a este [...] el probar el motivo que explicase el trato distinto que se llevó a cabo"7.

En línea con los estándares comparados del derecho antidiscriminación, en este caso las alegaciones fácticas y normativas del demandado, han de ser examinados con un estándar estricto de exigencia o de escrutinio; es decir, han de ser sometidas a un nivel de revisión cuya acuciosidad sea más intensa que aquella con la que se examinan habitualmente los argumentos ofrecidos por las partes en el proceso civil. La sana crítica

\footnotetext{
${ }^{5}$ Majmud con SEREMI de Obras Públicas, considerando $12^{\circ}$.

${ }^{6}$ Easton con Federación de Rodeo, considerando $11^{\circ}$.

${ }^{7}$ Rogel con Comité de agua potable rural Chauquén Bajo, considerando $11^{\circ}$.
} 
con que se han de evaluar las pruebas y los argumentos de las partes es, desde luego, compatible con esta atribución diferenciada de roles procesales; y debiera ser interpretada de esa manera con el fin de darle una hermenéutica pro discriminado a la misma.

\section{HACIA UNA REPARACIÓN DEL ACTO DISCRIMINATORIO EFECTIVA Y PREVENTORA}

Una interpretación finalista, sistemática y efectiva de la acción judicial contra la discriminación necesariamente tiene que cuestionar la denegación de justicia involucrada en lo que puede ser calificado como una verdadera inexistencia, en términos prácticos, de mecanismos reparatorios en la aplicación de la Ley de Medidas contra la Discriminación. Esto, por cuanto hasta el momento ninguna sentencia dictada en virtud de esta ley ha concedido una indemnización a los pocos demandantes por discriminación que han logrado obtener una sentencia favorable.

Una interpretación pro discriminado de la Ley $\mathrm{N}^{\circ} 20.609$, que pretenda cumplir eficazmente con el objetivo de dar una protección jurídica reforzada a los colectivos discriminados, necesariamente debe subsanar este déficit en materia de reparación de la discriminación. Para ello, los tribunales cuentan con las amplísimas potestades definidas en el artículo 12 de la Ley de Medidas contra la Discriminación, el que señala que si la sentencia de término declara que ha existido discriminación, tras dejar sin efecto el acto discriminatorio y disponer que no sea reiterado u ordenar que se realice el acto omitido, "[p]odrá también adoptar las demás providencias que juzgue necesarias para restablecer el imperio del derecho y asegurar la debida protección del afectado”. Cuesta, en ese sentido, aceptar que ningún tribunal se haya percatado de que el indemnizar a la víctima es una exigencia imprescindible si lo que se quiere es "restablecer el imperio del derecho" y darle "debida protección" al discriminado.

\section{La posibilidad de adjudicar reparación patrimonial en la sentencia de término}

La Ley de Medidas contra la Discriminación carece de una regulación de la atribución de reparación patrimonial o indemnización para la víctima de discriminación declarada como tal mediante sentencia de término. Esa carencia ha permitido que haya prevalecido una comprensión de dicha normativa que asume que ella prohíbe al juez dictaminar en la sentencia de término dicha reparación. Esa conclusión es incompatible con una hermenéutica pro discriminado de la Ley $\mathrm{N}^{\circ} 20.609$, la que debiera hacer valer dentro del procedimiento regulado por la acción contra la discriminación el principio general establecido en el artículo 2314 del Código Civil de la obligación de reparar patrimonialmente que nace para todo aquel que daña a otro mediante la comisión de un ilícito. No existe ninguna consideración normativa relevante que nos deba llevar a concluir que este principio general del derecho no se haya de aplicar en este tipo de procedimientos. Nada impide que la sentencia que concluya que ha habido un caso de discriminación dictamine la obligación del demandado de reparar patrimonialmente 
al demandante mediante una indemnización, cuya ejecución puede ser tramitada de acuerdo con las reglas del Código de Procedimiento Civil sobre cumplimiento incidental de las sentencias.

La importancia de la dictación de medidas de reparación simbólica y la necesidad de disponer de medidas de ajuste razonable y no reiteración

La falta de reflexión pertinente a la manera en que la discriminación se reproduce por medio de aparatos cognitivos perpetuados en nuestros discursos y nuestras prácticas ha llevado a que los tribunales no hayan reflexionado mucho acerca de la importancia de disponer de herramientas de reparación simbólica que contribuyan a transformar los estereotipos que sirven de sustrato sociocognitivo a la discriminación. La sentencia debe servir no solamente para reparar patrimonialmente al demandante, sino también para comunicarle a él y a la comunidad en general una señal de reproche hacia la conducta discriminatoria. Tanto los análisis y explicaciones del carácter discriminatorio de dicha conducta que la sentencia dé, como la multa a beneficio fiscal y la reparación patrimonial al demandante, son evidentemente señales claras que transmiten dicho reproche. Sin embargo, en ocasiones será conveniente que la sentencia disponga también de otras medidas, como el ofrecimiento de disculpas públicas por parte del individuo u organización que ha cometido el ilícito en cuestión. La adopción de medidas de reparación simbólica debe ser vista como una posibilidad de transformar los elementos culturales que permiten la discriminación. También es importante, como lo contempla el artículo 12 de la Ley $\mathrm{N}^{\circ}$ 20.609, que los jueces dispongan la no reiteración del acto discriminador cometido; y en aquellos casos en que sea apropiado, que determinen la adopción de medidas de ajuste razonable que permitan adecuar el entorno respectivo a las necesidades del grupo discriminado ${ }^{8}$. Este tipo de medidas debiera ser entendido como una posibilidad de poner fin a prácticas de trato desigual, ya sea directamente ordenando que ellas no se reiteren, o bien alterando las circunstancias materiales que las permiten.

\section{La necesidad de dar una interpretación restrictiva a la multa contemplada para el demandante que no ha probado la discriminación}

No todo es negativo en la jurisprudencia respecto de la acción contra la discriminación. El aspecto más positivo de ella es que ha aplicado de manera restrictiva la multa contemplada en el artículo 12 de la Ley N²0.609; de hecho, hasta el momento, dicha

${ }^{8}$ Este tipo de medidas, hasta el momento, han sido adoptadas solamente en casos relacionados con personas con capacidades diferentes; específicamente, en las sentencias Riesco con Servicio de Salud Ñuble, que dispuso la contratación de un asistente para una funcionaria no vidente, y García con Municipalidad de La Serena, que ordenó a un mall la construcción de una pasarela que permitiera el cruce de personas en silla de ruedas. Sin embargo, no es inconcebible que puedan ser conceptualizadas como medidas de ajuste razonable otras que busquen poner fin a tratos desaventajados que afecten a otros colectivos discriminados. 
sanción haya sido aplicada tan solo en un caso9 ${ }^{9}$ El problema, sin embargo, radica en la existencia misma de esta multa; como observara agudamente el asesor del Ministerio Secretaría General de la Presidencia que propuso esta norma, "la sola existencia de una norma en este sentido cumpliría un papel disuasivo" (Biblioteca del Congreso, 2012, 707). Evidentemente, una disposición como esta, intrínsecamente contraria al objetivo normativo de dar una protección reforzada a las víctimas de discriminación, debe ser objeto de una aplicación restrictiva, que la dictamine no solamente cuando la demanda haya carecido de "todo fundamento", al decir del artículo 12, sino también cuando el demandante haya exhibido una actitud particularmente frívola ante el ejercicio de esta acción.

\section{Reflexiones finales: desafíos del derecho antidiscriminación para jueces, académicos y litigantes}

La Ley No 20.609, de Medidas contra la Discriminación, contiene significativas deficiencias, que se han visto o bien confirmadas o bien amplificadas por una jurisprudencia por lo general demasiado formalista. Esto podría sugerir el clásico problema del huevo y la gallina: ¿qué debemos solucionar, las deficiencias de la Ley Antidiscriminación, o los criterios con los que la comunidad profesional interpreta y aplica este y otros textos legales? La pregunta, en todo caso, no necesita ser entendida como una disyuntiva insoluble: ambas cosas son necesarias. La transformación de la cultura jurídica, con el fin de hacerla más receptiva y sensible al contexto social, depende de los propios integrantes de la comunidad jurídica. En la medida en que nuestra comunidad de profesionales del derecho reconozca el rol creativo que le corresponde en la puesta en uso de las normas, nuestra cultura jurídica cobrará la capacidad de desarrollar estrategias jurídicas en materia de discriminación efectivas y adecuadas a la realidad social en la que vivimos. De ahí que la conclusión de este texto sea una invitación a la comunidad jurídica a que se disponga a contribuir en la consecución de los objetivos de las normas contra la discriminación, colaborando con lo que ya ha sido hecho por los legisladores, pero evitando transformarlo en un límite a la virtud de los juristas, conocedores de las necesidades conceptuales que nacen de la aplicación de las normas a la realidad. De ahí que el desafío principal que nos presenta el derecho antidiscriminación no sea otro que el de renovar nuestra cultura jurídica.

La transformación de nuestra cultura jurídica para hacer frente al fenómeno social de la discriminación supone atribuir cierto tipo de metas para la doctrina, y cierto tipo de responsabilidades para la judicatura. La doctrina, y particularmente aquella producida desde la academia, debiera contribuir a clarificar las maneras en que la Ley $\mathrm{N}^{\circ} 20.609$ puede ser interpretada de una manera que satisfaga efectivamente el propósito

${ }^{9}$ Se trata de la sentencia Quinteros con Universidad Andrés Bello, causa rol No 17928-2015, dictada por el 29 Juzgado Civil de Santiago el 14 de septiembre de 2016, en la que el tribunal respectivo rechazó una demanda presentada por una estudiante de derecho en que reclamaba contra la diferencia entre las modalidades del examen de grado en dos sedes distintas de dicha universidad, aseverando que dicha pretensión carecía de todo fundamento. 
de proporcionar una protección jurídica reforzada contra la discriminación que afecta a numerosos colectivos discriminados. La judicatura, por su parte, debiera reconocer que debe readecuar el aparataje conceptual con que resuelve las causas que le son sometidas a su conocimiento mediante la acción judicial contra la discriminación, pues ese aparataje conceptual ha permitido que los tribunales se hayan transformado, según una común expresión, en parte del problema y no de la solución en materia de protección a las personas discriminadas.

\section{BIBLIOGRAFÍA}

Atria, Fernando. 1997. Los Peligros de la Constitución: La Idea de Igualdad en la Jurisprudencia Nacional. Santiago, Chile: Universidad Diego Portales.

Biblioteca del Congreso. 2012. "Historia de la Ley No 20.609".

Bordalí, Andrés. 2006. "El recurso de protección entre exigencias de urgencia y seguridad jurídica”. Revista de Derecho (Valdivia) 19 (2): 205-28.

Bordalí, Andrés. 2013. "La igualdad de las partes en los procesos judiciales chilenos". En Igualdad, inclusión y derecho: lo político, lo social y lo jurídico en clave igualitaria, editado por Fernando Muñoz, 217-39. Santiago: LOM.

Casas, Lidia, y Catalina Lagos. 2014. "Análisis Crítico de La Acción de No Discriminación Arbitraria a La Luz de Los Primeros Casos”. Anuario de Derechos Humanos 10: 127-37.

Coddou, Alberto, Judith Schönsteiner, y Tomás Vial. 2013. "La Ley Antidiscriminación: avances e insuficiencias en la protección de la igualdad y la no discriminación en Chile". Informe Anual sobre Derechos Humanos en Chile (UDP) 11: 285-309.

Coddou, Alberto, y Tomás Vial. 2013. "Estándares y criterios para la creación de un órgano antidiscriminación en Chile: desafíos pendientes y opciones institucionales". Anuario de Derecho Público 4: 216-33.

Couso, Javier A. 2005. "The Judicialization of Chilean Politics: The Rights Revolution That Never Was". En The Judicialization of Politics in Latin America, editado por Rachel Sieder, Line Schjolden, y Alan Angell, 105-29. New York: Palgrave Macmillan.

DíAZ de VALdÉs, José Manuel. 2013. “¿Es la Ley Zamudio Verdaderamente una Ley General Antidiscriminación?”. Actualidad Jurídica 28: 279-97.

DíAz, Iván. 2013. "Ley chilena contra la discriminación: una evaluación desde los derechos internacional y constitucional". Revista Chilena de Derecho 40 (2): 635-68.

Figueroa, Rodolfo, y Gastón Gómez. 2000. Discriminación en contra la mujer y recurso de protección. Informes de investigación (Centro de Investigación Jurídica) 8. Santiago: Universidad Diego Portales.

Khaitan, Tarunabh. 2014. A Theory of Discrimination Law. Oxford: Oxford University Press.

Movimiento de Inclusión y Liberación Homosexual. 2002. "I Informe Anual de Derechos Humanos de la Diversidad Sexual en Chile". Santiago.

Movimiento de Inclusión y Liberación Homosexual. 2013. "XII Informe Anual de Derechos Humanos de la Diversidad Sexual en Chile". Santiago.

Movimiento de Inclusión y Liberación Homosexual. 2015. "XIV Informe Anual de Derechos Humanos de la Diversidad Sexual en Chile". Santiago.

MuÑOZ, Fernando. 2015. "Estándares conceptuales y cargas procesales en el litigio antidiscriminación. Análisis crítico de la jurisprudencia sobre Ley Zamudio entre 2012 y 2015”. Revista de Derecho (Valdivia) 28: 145-67. 
REPERTORIO de Legislación y Jurisprudencia chilenas. 1996. Santiago: Editorial Jurídica de Chile.

Ugarte, José Luis. 2009. "Tutela laboral de derechos fundamentales y carga de la prueba". Revista de Derecho (Valparaíso), No 33: 215-28.

VIAL, Tomás. 2013. "La nueva Ley Antidiscriminación: propuestas para avanzar en su perfeccionamiento". Anuario de Derechos Humanos 9: 183-91.

\section{Sentencias citadas}

Juzgado de Letras de Lautaro, Easton con Federación de Rodeo, sentencia de 5 de diciembre de 2013, Rol No 318-2012.

$4^{\circ}$ Juzgado de Letras de Antofagasta, Majmud con SEREMI de Obras Públicas, sentencia de 30 de junio de 2014, Rol No 5451-2013.

1er Juzgado de Letras de Chillán, Riesco con Servicio de Salud Ñuble, sentencia del 1 de agosto de 2014, Rol No 1901-2014.

$29^{\circ}$ Juzgado Civil de Santiago, Quinteros con Universidad Andrés Bello, sentencia de 14 de septiembre de 2016, Rol No 17928-2015.

$2^{\circ}$ Juzgado de Letras de La Serena, García con Municipalidad de La Serena, sentencia del 14 de septiembre de 2016, Rol No 2903-2015.

JuzGado de Letras de Panguipulli, Rogel con Comité de agua potable rural Chauquén Bajo, sentencia de 24 de abril de 2017, Rol No 151-2016. 